\title{
2. SYNOPSIS
}

\begin{tabular}{|c|c|}
\hline $\begin{array}{l}\text { Name of Sponsor: I.R.I.S., } 50 \text { rue Carnot - } 92284 \text { Suresnes Cedex - France } \\
\text { Les Laboratoires Servier, } 50 \text { rue Carnot - } 92284 \text { Suresnes Cedex - France }\end{array}$ & $\begin{array}{l}\text { (For National } \\
\text { Authority Use only) }\end{array}$ \\
\hline $\begin{array}{l}\text { Test drug } \\
\text { Name of Finished Product: } \\
\text { NA } \\
\text { Name of Active Ingredient: } \\
\text { Micronized purified flavonoid fraction (S 05682) }\end{array}$ & \\
\hline Individual Study Table Referring to Part of the Dossier & Page: \\
\hline
\end{tabular}

Title of study: Clinical acceptability study between micronized purified flavonoid fraction (MPFF) $1000 \mathrm{mg}$ tablets and micronized purified flavonoid fraction $500 \mathrm{mg}$ tablets after 7 days of treatment followed by a follow-up period of 7 days in patients suffering from acute hemorrhoidal disease (HD).

International, multicenter, double-blind, randomized, parallel group study.

Protocol No.: CL3-05682-108.

The description of the study protocol given hereafter includes the modifications of the substantial amendment No.1 to the protocol.

International coordinator:

Study centres:

Overall, 14 centres located in 2 countries included at least one patient: 9 centres in Russia (100 included patients) and 5 centres in Serbia (62 included patients).

Publication (reference): Not Applicable.

\section{Studied period:}

Initiation date: 16 December 2013 (date of first visit first patient)

Phase of development of the study:

Completion date: 14 June 2014 (date of last visit last patient)

\section{Objectives:}

The objective of this phase III study was to compare the clinical acceptability between micronized purified flavonoid fraction $1000 \mathrm{mg}$ tablets and micronized purified flavonoid fraction $500 \mathrm{mg}$ tablets (3 grams per day during 4 days and 2 grams per day during the 3 following days) by oral route in patients suffering from symptoms related to acute hemorrhoidal disease.

\section{Methodology:}

International, multicentre, double-blind, randomized, parallel group, phase III study comparing the acceptability of MPFF $1000 \mathrm{mg}$ versus MPFF $500 \mathrm{mg}$ in out-patients for an acute haemorrhoidal episode. Method of treatment allocation was balanced non-centralised, non-adaptive; treatment allocation was performed according to the randomisation list using permutation block.

This study was performed in strict accordance with Good Clinical Practice including the archiving of essential documents.

\section{Number of patients:}

Planned: 150 (75 patients under MPFF $1000 \mathrm{mg}$ and 75 patients under MPFF $500 \mathrm{mg}$ ).

Included: 162 (79 patients under MPFF $1000 \mathrm{mg}$ and 83 patients under MPFF $500 \mathrm{mg}$ ).

\section{Diagnosis and main criteria for inclusion:}

Active male or female patient aged between 18 to 75 years old (included); presenting in out-patient facility with an acute haemorrhoidal episode (internal and/or external) of recent onset (5 days or less before inclusion), with an acute pain with oedema assessed by a VAS and/or bleeding evaluated by a 4 point-scale. The episode should be non-treated and non-complicated.

\section{Test drug:}

MPFF, tablets of $1000 \mathrm{mg}, 7$ days of treatment as follow: 3 tablets per day for the first 4 days taken p.o. (one tablet in the morning, one tablet at midday and one tablet in the evening i.e. $3 \mathrm{~g} /$ day). Then 2 tablets per day during the 3 following days: one in the morning and one at midday i.e. $2 \mathrm{~g} /$ day.

Batch No.: L0049608 
Comparator (Reference product):

MPFF, tablets of $500 \mathrm{mg}, 7$ days of treatment as follow: 6 tablets per day for the first 4 days taken p.o. ( 2 tablets in the morning, 2 tablets at midday and 2 tablets in the evening i.e. $3 \mathrm{~g}$ /day). Then 4 tablets per day during the 3 following days: 2 in the morning and 2 at midday i.e. $2 \mathrm{~g} / \mathrm{day}$.

Placebo $1000 \mathrm{mg}$ and placebo $500 \mathrm{mg}$ tablets were also administered to maintain the blind.

Duration of treatment:

- A 7 days double-blind treatment period (P1 from D1 to D4 then P2 from D5 to D7).

- A 7 days follow-up period without treatment (from D8 to D14).

Criteria for evaluation:

Efficacy measurement:

Not applicable.

\section{Safety measurements:}

- Adverse events reported at each visit.

- Laboratory tests: biochemical and haematological parameters were performed at selection (D0) and at D7.

- Vital signs: sitting blood pressure and heart rate were assessed at selection (D0) and D7.

- Weight was assessed at selection (D0) and D7.

- Bleeding cessation was to be assessed at selection (D0) and D7 on a 4-point-scale (hematochezia assessment scale and bleeding frequency).

- Pain evaluation: anal pain assessment was performed at selection (D0) and D7 on a VAS.

According to Amendment No. 1: "The safety criteria were assessed only if the patient came with less than 3 days after treatment discontinuation".

\section{Other measurements:}

- Score of constipation, score of stools consistency and dietary habits were evaluated at D0 and D7.

- Anuscopy examination was performed at D0; then at D7 if necessary.

- Urinary pregnancy test. Test was sampled, assayed on site and reviewed by the investigator at D0.

\section{Statistical methods:}

\section{Analysis Set:}

Safety analyses were performed in the Safety Set i.e. all included patients having received at least one study treatment intake.

Efficacy analysis:

Not applicable.

Study outcome and safety analysis: Descriptive statistics were provided by treatment groups and overall.

\section{SUMMARY - CONCLUSIONS \\ DISPOSITION OF PATIENTS AND ANALYSIS SETS}

Disposition of patients

\begin{tabular}{|c|c|c|c|c|}
\hline Status & & MPFF $1000 \mathrm{mg}$ & MPFF 500 mg & All \\
\hline Included and randomised & $\mathbf{n}$ & 79 & 83 & 162 \\
\hline in compliance with the protocol & $\mathrm{n}$ & 73 & 77 & 150 \\
\hline with a protocol deviation before or at inclusion & $\mathrm{n}$ & 6 & 6 & 12 \\
\hline Withdrawn due to & n (\%) & $3(3.8)$ & - & $3(1.9)$ \\
\hline adverse event & $\mathrm{n}$ & 2 & - & 2 \\
\hline protocol deviation & $\mathrm{n}$ & 1 & - & 1 \\
\hline Completed & n $(\%)$ & $76(96.2)$ & 83 (100) & $159(98.1)$ \\
\hline in compliance with the protocol & $\mathrm{n}$ & 71 & 80 & 151 \\
\hline with a protocol deviation after inclusion & $\mathrm{n}$ & 5 & 3 & 8 \\
\hline Safety Set & n (\%) & $79(100)$ & $83(100)$ & $162(100)$ \\
\hline
\end{tabular}

A total of 162 patients were included and randomly assigned to one of the 2 groups: 79 patients in the MPFF $1000 \mathrm{mg}$ group and 83 patients in the MPFF $500 \mathrm{mg}$ group. The planned balanced distribution was reached.

In the Randomised Set, 3 patients were withdrawn from the study, all at D007, in the MPFF 1000 mg group: 2 due to non-serious adverse event of mild intensity (lip swelling and dermatitis) and 1 due to protocol deviation (age $<18$ years at inclusion). 


\section{SUMMARY - CONCLUSIONS (Cont'd)}

In all, 12 protocol deviations were observed before or at inclusion (6 in each MPFF group): they all concerned study management, mainly biology (6 deviations in 6 patients, 3.7\%) and study treatment dispensation ( 5 deviations in 5 patients, $3.1 \%$ ). Similar data were observed in both groups.

After inclusion, 23 protocol deviations were observed with a higher number in the MPFF $1000 \mathrm{mg}$ group (19 deviations in 8 patients) than in the MPFF $500 \mathrm{mg}$ group (4 deviations in 3 patients), all related to study management. The most frequent deviations concerned unauthorized concomitant treatment ( 6 deviations in 5 patients), dose change (6 deviations in 4 patients), mainly "dose change at D005 morning not done" (4 deviations in 4 patients) and study treatment administration (6 deviations in 4 patients), mainly "overall duration of study $<7$ days" ( 3 deviations in 3 patients).

\section{BASELINE CHARACTERISTICS}

Main baseline characteristics in the Randomised Set are summarised in the Table below:

Main baseline characteristics at inclusion in the Randomised Set

\begin{tabular}{|c|c|c|c|c|}
\hline & & $\begin{array}{l}\text { MPFF 1000 mg } \\
(\mathrm{N}=79)\end{array}$ & $\begin{array}{c}\text { MPFF 500 mg } \\
(\mathbf{N}=\mathbf{8 3})\end{array}$ & $\begin{array}{c}\text { All } \\
(\mathrm{N}=162) \\
\end{array}$ \\
\hline Age (years) & $\begin{array}{r}\mathrm{n} \\
\text { Mean } \pm \text { SD } \\
\text { Min ; Max }\end{array}$ & $\begin{array}{c}79 \\
41.4 \pm 12.7 \\
17 ; 68\end{array}$ & $\begin{array}{c}83 \\
42.6 \pm 14.2 \\
18 ; 75\end{array}$ & $\begin{array}{c}162 \\
42.0 \pm 13.5 \\
17 ; 75\end{array}$ \\
\hline $\begin{array}{r}\text { Male } \\
\text { Female }\end{array}$ & $\begin{array}{l}\mathrm{n}(\%) \\
\mathrm{n}(\%)\end{array}$ & $\begin{array}{l}42(53.2) \\
37(46.8)\end{array}$ & $\begin{array}{l}48(57.8) \\
35(42.2)\end{array}$ & $\begin{array}{l}90(55.6) \\
72(44.4)\end{array}$ \\
\hline BMI $\left(\mathrm{kg} / \mathrm{m}^{2}\right)$ & $\begin{array}{r}n \\
\text { Mean } \pm \text { SD } \\
\text { Min ; Max }\end{array}$ & $\begin{array}{c}79 \\
25.5 \pm 5.3 \\
17.7 ; 48.4\end{array}$ & $\begin{array}{c}83 \\
26.3 \pm 5.2 \\
15.1 ; 40.8\end{array}$ & $\begin{array}{c}162 \\
25.9 \pm 5.3 \\
15.1 ; 48.4\end{array}$ \\
\hline Caucasian & $\mathrm{n}(\%)$ & $79(100)$ & $83(100)$ & $162(100)$ \\
\hline Haemorrhoidal disease duration (days) & $\begin{array}{r}n \\
\text { Mean } \pm \text { SD } \\
\text { Min ; Max }\end{array}$ & $\begin{array}{c}75 \\
2.5 \pm 1.2 \\
0 ; 5\end{array}$ & $\begin{array}{c}79 \\
2.4 \pm 1.3 \\
0 ; 5\end{array}$ & $\begin{array}{c}154 \\
2.5 \pm 1.2 \\
0 ; 5\end{array}$ \\
\hline $\begin{array}{r}\text { Previous treatments for haemorrhoidal disease } \\
\text { Yes } \\
\text { No }\end{array}$ & $\begin{array}{l}\mathrm{n}(\%) \\
\mathrm{n}(\%)\end{array}$ & $\begin{array}{c}1(1.3) \\
78(98.7)\end{array}$ & $83(100)$ & $\begin{array}{c}1(0.6) \\
161(99.4)\end{array}$ \\
\hline
\end{tabular}

At inclusion, the haemorrhoidal disease had been lasted for $2.5 \pm 1.2$ days, on average; only one patient (in the MPFF $1000 \mathrm{mg}$ group) received a previous treatment for haemorrhoidal disease (not for the current episode): it consisted in local hemostatic (collagen), stopped more than 1 month before the selection. Regarding previous non-drug treatments, as required in the protocol, no patient reported laser therapy, anal surgery or canal radiation (to note, missing data reported for 60 patients $(37.0 \%)$ regarding laser therapy and canal radiation and 63 patients $(38.9 \%)$ regarding anal surgery without relevant difference between groups).

Overall, 86 patients (53.1\%) reported at least one medical history other than haemorrhoidal disease (37 patients, $46.8 \%$ in the MPFF $1000 \mathrm{mg}$ group and 49 patients, $59.0 \%$ in the MPFF $500 \mathrm{mg}$ group), mainly related to Vascular disorders (34 patients, 21.0\%). At inclusion, 45 patients (27.8\%) had taken at least one concomitant treatment (21 patients, $26.6 \%$ in the MPFF $1000 \mathrm{mg}$ group and 24 patients, $28.9 \%$ in the MPFF $500 \mathrm{mg}$ group). The most frequent were beta blocking agents and agents acting on the renin-angiotensin system (18 patients, $11.1 \%$ for both).

On average, at inclusion, sitting SBP was $124.0 \pm 13.0 \mathrm{mmHg}$, sitting DBP was $79.5 \pm 9.6 \mathrm{mmHg}$ and sitting HR was $71.7 \pm 7.0 \mathrm{bpm}$.

No clinically relevant difference between groups was observed regarding demographic data, disease characteristics and other baseline characteristics. 


\section{SUMMARY - CONCLUSIONS (Cont'd) \\ EXTENT OF EXPOSURE/TREATMENT DURATION}

In the Randomised Set, global treatment duration ranged between 1 and 7 days with a mean $( \pm S D)$ of $6.9 \pm 0.7$ days (median of 7.0 days) with similar results in both groups. Global exposure to treatment (days), defined as global treatment duration minus the number of days of interruption, was similar to the global treatment duration.

As Safety Set (SS) was identical to Randomised Set (RS), results in the SS and in the RS were the same.

The compliance was good and similar in both groups, on average $94.2 \pm 11.1 \%$; for $97.5 \%$ of patients, the compliance was included in the $[80 ; 120] \%$ range.

\section{SAFETY RESULTS}

\section{- Adverse events}

\section{Overall summary of adverse events in the Safety Set}

\begin{tabular}{|c|c|c|c|}
\hline & & $\begin{array}{l}\text { MPFF 1000 mg } \\
(\mathrm{N}=79)\end{array}$ & $\begin{array}{c}\text { MPFF 500 mg } \\
\quad(\mathrm{N}=83)\end{array}$ \\
\hline \multicolumn{4}{|l|}{ Patients having reported } \\
\hline at least one emergent adverse event & $\mathrm{n}(\%)$ & $15(19.0)$ & $10(12.0)$ \\
\hline at least one treatment-related emergent adverse event & $\mathrm{n}(\%)$ & $3(3.8)$ & $2(2.4)$ \\
\hline \multicolumn{4}{|l|}{ Patients having experienced } \\
\hline at least one serious adverse event (including death) & $\mathrm{n}(\%)$ & - & - \\
\hline at least one treatment-related serious adverse event & $\mathrm{n}(\%)$ & - & - \\
\hline \multicolumn{4}{|l|}{ Patients with treatment withdrawal } \\
\hline due to an emergent adverse event & $\mathrm{n}(\%)$ & $2(2.5)$ & - \\
\hline due to an emergent serious adverse event & $\mathrm{n}(\%)$ & - & - \\
\hline due a treatment-related emergent adverse event & $\mathrm{n}(\%)$ & $2(2.5)$ & - \\
\hline Patients who died & $\mathrm{n}(\%)$ & - & - \\
\hline
\end{tabular}

Overall 25 patients reported at least one emergent adverse event with a rate of $19.0 \%$ in the MPFF $1000 \mathrm{mg}$ group versus $12.0 \%$ in the MPFF $500 \mathrm{mg}$ group. No severe emergent adverse event was reported. No death or other serious adverse event was reported during the study.

In the MPFF $1000 \mathrm{mg}$ group, the most frequently affected System Organ Class (SOC) (more than 2 patients affected) were gastrointestinal disorders and nervous system disorders, without relevant difference between groups $(8.9 \%$ versus $6.0 \%$ and $5.1 \%$ versus $2.4 \%$, respectively in the MPFF $1000 \mathrm{mg}$ and $500 \mathrm{mg}$ groups). In addition to gastrointestinal disorders, the most frequently reported SOC in the MPFF $500 \mathrm{mg}$ group was investigations (3.6\%), without relevant difference compared to the MPFF $1000 \mathrm{mg}$ group (1.3\%).

In the MPFF $1000 \mathrm{mg}$ group, the most frequent (reported by at least 2 patients) emergent adverse event was headache: 3 patients, $3.8 \%$ in the MPFF $1000 \mathrm{mg}$ group versus one, $1.2 \%$ in the MPFF $500 \mathrm{mg}$ group. All other emergent adverse events in the MPFF $1000 \mathrm{mg}$ group were reported by only one patient.

In the MPFF $500 \mathrm{mg}$ group, the most frequent emergent adverse events (at least 2 patients) were diarrhoea and nausea reported by 2 patients, $2.4 \%$ for each, with quite similar frequencies in the MPFF $1000 \mathrm{mg}$ group (1 patient, $1.3 \%$ for each) and, aspartate aminotransferase increased and dry mouth both reported by 2 patients in the MPFF $500 \mathrm{mg}$ versus none in the MPFF $1000 \mathrm{mg}$ group.

Most emergent adverse events were of mild intensity: 76.9\% in the MPFF $1000 \mathrm{mg}$ group and all in the MPFF $500 \mathrm{mg}$ group. In the MPFF $1000 \mathrm{mg}$ group, $23.1 \%$ of the EAES were reported as moderate.

Overall, 5 patients had 10 emergent adverse events considered as treatment-related according to the investigator, without relevant difference between groups: 3 patients $(3.8 \%)$ in the MPFF $1000 \mathrm{mg}$ group reported 6 treatment-related EAEs (nausea, hypoaesthesia oral, lip swelling, dermatitis allergic, erythema and dizziness) and 2 patients (2.4\%) in the MPFF $500 \mathrm{mg}$ group reported 4 treatment-related EAEs (nausea, dry mouth (2) and diarrhoea). All treatment-related emergent adverse events in the MPFF $1000 \mathrm{mg}$ group were reported once. 


\section{SUMMARY - CONCLUSIONS (Cont'd) SAFETY RESULTS (Cont'd)}

Overall 2 patients withdrew for EAE (lip swelling and dermatitis allergic) both in the MPFF $1000 \mathrm{mg}$ group. These EAEs were both non-serious, rated as mild intensity and considered as related to the study drug according to the investigator. They resolved within 3 days or less (without treatment for lip swelling).

All emergent adverse events but 2 (24 events, 92.3\%) recovered in the MPFF $1000 \mathrm{mg}$ group versus 12 events, $(75.0 \%)$ in the MPFF $500 \mathrm{mg}$ group. Overall, 5 emergent adverse events did not recover: 1 event in the MPFF $1000 \mathrm{mg}$ group $(3.8 \%)$ and 4 events $(25.0 \%)$ in the MPFF $500 \mathrm{mg}$ group, none of them was considered as treatment-related according to the investigator.

Overall, 2 patients reported at least one adverse event after the treatment period (last study drug intake + 3 days). One patient in the MPFF $1000 \mathrm{mg}$ group reported 3 adverse events (gamma-glutamyl transferase increased, alanine aminotransferase increased and aspartate aminotransferase increased 11 days after the last study drug intake) and one patient in the MPFF $500 \mathrm{mg}$ group reported haemorrhoidal haemorrhage 5 days after the last study drug intake. All the adverse events were of mild intensity, not serious and resolved.

\section{- Laboratory tests}

Overall 2 biochemical emergent PCSA (Potentially Clinically Significant Abnormal) values, both in the MPFF $500 \mathrm{mg}$ group, were reported: high gamma glutamyl transferase value and low protein value.

Haematological emergent PCSA values were sparse in both groups: they consisted in low haemoglobin (no patient in the MPFF $1000 \mathrm{mg}$ group versus one (1.2\%) in the MPFF $500 \mathrm{mg}$ group) and low prothrombin time (1 patient, $1.4 \%$ in the MPFF $1000 \mathrm{mg}$ group versus 2 patients, $2.4 \%$ in the MPFF $500 \mathrm{mg}$ group).

\section{- Vital signs and clinical examination}

Neither clinically relevant changes nor differences between groups in mean/median values over time were detected regarding weight, blood pressure and heart rate.

\section{- Bleeding cessation}

The percentage of patients with aggravation of bleeding from baseline to D007 was $4.1 \%$ (3 patients) in the MPFF $1000 \mathrm{mg}$ group and 2.4\% (2 patients) in the MPFF $500 \mathrm{mg}$ group.

An improvement in bleeding (including patients with complete cessation) was observed for most of the patients in both groups: $55.7 \%$ (44 patients) in the MPFF $1000 \mathrm{mg}$ group versus $61.5 \%$ (51 patients) in the MPFF $500 \mathrm{mg}$ group. A complete cessation of bleeding was observed for about half of the patients: $46.8 \%$ (37 patients) in the MPFF $1000 \mathrm{mg}$ group versus $54.2 \%$ (45 patients) in the MPFF $500 \mathrm{mg}$ group. Of note, the percentage of patients with moderate or severe bleeding at baseline was numerically higher in the MPFF $1000 \mathrm{mg}$ group (46.8\%) than in the MPFF $500 \mathrm{mg}$ group (28.9\%).

In each group, the percentage of patients without bleeding increased from baseline to D007: from $25.6 \%$ to $73.0 \%$ in the MPFF $1000 \mathrm{mg}$ group and from $30.5 \%$ to $86.6 \%$ in the MPFF $500 \mathrm{mg}$ group.

\section{- Anal pain}

Anal pain (assessed on VAS), decreased from baseline to D007, in both groups: $-2.4 \pm 2.0 \mathrm{~cm}$ and $-2.2 \pm 2.2 \mathrm{~cm}$ in MPFF $1000 \mathrm{mg}$ and $500 \mathrm{mg}$ groups, respectively.

\section{CONCLUSION}

This international multicentre double-blind, randomised phase III study conducted in patients with acute haemorrhoidal episode showed that MPFF $1000 \mathrm{mg}$ was well tolerated. No relevant difference with MPFF $500 \mathrm{mg}$ was observed regarding adverse events, laboratory parameters, vital signs, clinical examination, bleeding and anal pain. In the light of the Reference Safety Information in force (version dated February 2014), no unexpected adverse event was reported.

Date of the report: 23 December 2014

Version of the report: Final version 